\title{
Los Medios de Comunicación en el Perú y la Tendencia Global

\author{
A propósito del ensayo La Civilización del Espectáculo
}

Media in Perú and the global trend.

Regarding the essay on the civilization of entertainment

Cecilia Gabriela González Fuentes*

¿Que quiere decir Civilización del espectáculo?: Un mundo donde el primer lugar en la tabla de valores vigente lo ocupa el entretenimiento, $y$ donde divertirse, escapar del aburrimiento, es la pasión universal. Sus consecuencias son: la banalización de la cultura, la generalización de la frivolidad y, en el campo de la información, que prolifere el periodismo irresponsable de la chismografia y el escándalo.

Mario Vargas Llosa

La civilización del espectáculo.

\section{Resumen}

El artículo presenta las principales ideas del escritor peruano-español Mario Vargas Llosa en torno al fenómeno del desplazamiento de la cultura tradicional por la cultura de masas y el entretenimiento. A partir de ello, pasa a analizar los contenidos de los medios de comunicación peruanos, presentando casos puntuales en que se exhibe o se ha ejercido alguna forma de violencia que atenta contra los derechos fundamentales de las personas; además, informa de su tratamiento a nivel local e internacional. Seguidamente, propone una reflexión sobre el impacto de la violencia como espectáculo así como sobre la necesidad de promover cambios cualitativos que permitan la adecuación progresiva de los medios de comunicación a los fines sociales que la Constitución Política y la legislación les asignan. Identifica, además, los mecanismos de regulación y control existentes, considerándolos oportunidades para que el ciudadano común participe del cambio que la realidad demanda.

\footnotetext{
* Abogada por la Universidad Nacional de San Agustín de Arequipa, con estudios de Maestría en Derecho con mención en Función Jurisdiccional por la Pontificia Universidad Catolica del Perú. Ha sido Jueza de Familia de Lima (2002-2013) y actualmente se desempeña como Fiscal Superior de Familia de Lima.
}

Fecha de aceptación: 23/09/2014

Fecha de recepción: 27/10/2014 


\title{
Palabras clave
}

CONCORTV, Cultura, Derechos humanos, Entretenimiento, Espectro radio eléctrico, Ética, Infracción, Internet, Libertad de expresión, Medios de comunicación, Mujeres, Morbo, Niños y adolescentes, Radio, Tecnología, Televisión, Violencia.

\begin{abstract}
This article shows the main ideas of the Peruvian-Spanish writer Mario Vargas Llosa on the phenomenon of how traditional culture is being displaced by mass culture and entertainment. Based on such analysis, the article examines the contents of the Peruvian media, presenting specific cases showing some form ofviolence violating the fundamental rights of individuals; while describing the way such cases are treated at local and international levels. Then, the author proposes a reflection on the impact of the violence portrayed in entertainment and on the need to promote qualitative changes allowing for the gradual adaptation of the media to the social purposes it is expected to pursue in light of the Constitution and laws. It also identifies existing regulatory and oversight mechanisms, considering them opportunities for ordinary citizens to participate in the change that reality demands.
\end{abstract}

\section{Key words}

CONCORTV, Culture, Civilization, Human Rights, Entertainment, Radio Electric Spectrum, Ethics, Infringement, Internet, Freedom of Expression, Media Women, Ghoulish, Children and Adolescents, Radio, Technology, TV, Violence.

En el Perú de hoy, donde los padres y madres se esfuerzan por generar recursos trabajando fuera de casa y los artefactos estrella del hogar son la televisión y la computadora, no cabe duda que la formación cultural de los hijos se nutre, en gran medida, de la incesante información que proviene de los medios de comunicación. Al mismo tiempo, niños, jóvenes y adultos formamos parte de un colectivo social que mansamente recibe el bombardeo de la publicidad, esa que nos demanda vivir de acuerdo a las "tendencias", esencialmente consumir, bajo determinados patrones -marcados por intereses económicos- a riesgo de quedar desfasados y ser considerados "out" o "nerd"; en otras palabras: sujetos extraños que no forman parte del "buen vivir" consagrado tácitamente para los tiempos.

En el ensayo "La Civilización del Espectáculo", Mario Vargas Llosa postula que la cultura, en el sentido tradicional de la palabra -entendida como patrimonio de un selecto grupo intelectual- está desapareciendo: La democratización de la cultura, la buena voluntad de ponerla al alcance de 
todos a través de la educación y la promoción de las artes, ha traído como consecuencia su degradación, siendo entendida, apenas, como una manera agradable de pasar el tiempo. Al mismo tiempo que la cultura se ha masificado, las expresiones culturales son ahora más banales y frívolas, más ligth. Paralelamente, ante el incremento del laicismo, la necesidad de una orientación ética que correspondería a la alta cultura -representada por la filosofía, la ciencia, la literatura y las artes- no puede ser cubierta por la cultura de masas imperante, al estar ésta caracterizada por la superficialidad. La cultura-mundo, según afirma Frédéric Martel, se ha tornado hoy en la cultura del entretenimiento, ésta no se expresa a través de libros, sino en películas, programas de televisión, videojuegos, mangas, conciertos de rock, pop o rap, videos y tabletas, es decir las diversiones del gran público, que han ido reemplazando a la cultura del pasado. ${ }^{1}$

Nuestro escritor da un paseo por diferentes ideas que describen los cambios que se han venido presentando en algo más de medio siglo. Cita en principio a T.S. Eliot quien, en 1948 afirmaba que la familia era el vehículo natural de transmisión de la cultura, entendida no solamente como conocimiento sino como estilo de vida, de modo que, cuando esa institución fundamental no es funcional" el resultado es el "deterioro de la cultura" agregando: "... no veo razón alguna por la cual la decadencia de la cultura no pueda continuar y no podamos anticipar un tiempo, de alguna duración, del que se pueda decir que carece de cultura". ${ }^{2}$ Seguidamente, cita a George Steiner quien, en los años setenta ya advertía: "La palabra está cada vez más subordinada a la imagen"; 3

Vargas Llosa nos introduce a los elementos de la cultura de masas: "nace con el predominio de la imagen y el sonido, es decir con la pantalla. (...) Este proceso se ha acelerado con la revolución cibernética, la creación de las redes sociales y la universalización de Internet. No sólo la información ha roto todas las barreras y se ha puesto al alcance de todo el mundo, prácticamente todos los dominios de la comunicación, del arte, de la politica, del deporte, de la religión, etcétera, han experimentado los efectos reformadores de la pequeña pantalla". ${ }^{4}$

\footnotetext{
${ }^{1}$ Vargas Llosa, Mario. (2012) La Civilización del Espectáculo. Pag. 15. Editorial Alfaguara. Primera Edición. Marzo. pp. 20-21. T.S. Eliot Notes Towards the Definition of Culture. Citado por Mario Vargas Llosa, La Civilización del Espectáculo. Pag. 15. Editorial Alfaguara. Primera Edición. Marzo de 2012. pp.9.

3 George Steiner. In Bluebeard's Castle. Some Notes Towards the Redefinition of Culture. Citado por Mario Vargas Llosa. Op. Cit.

4 Gilies Lipovetsky y Jean Serroy. (2010) La cultura mundo. Respuesta a una sociedad desorientada. Barcelona. Anagrama. Colección argumentos. Citado por Mario Vargas Llosa. Op. Cit.
} 
En efecto, el cine, particularmente, la pantalla de la televisión y hoy la Internet se hallan omnipresentes como una ventana hacia todo lo existente -lo más valioso y también lo más deleznable de la creación humana- pero, además, se constituyen en un condicionante permanente, en la medida que canalizan y privilegian determinados contenidos en detrimento de otros. Vargas Llosa considera nefasta la influencia de los medios en las personas y nos dice: "La cultura mundo, en vez de promover al individuo, lo aborrega, privándolo de lucidez y libre albedrío, y lo hace reaccionar ante la "cultura" imperante de manera condicionada y gregaria, como los perros de Pavlov ante la campanita que anuncia la comida ${ }^{\prime 5}$ Cita también a Marshall McLuhan quien hace más de medio siglo aseguró "Que los medios no son nunca meros vehículos de un contenido, que ejercen una solapada influencia sobre éste, y que, a largo plazo, modifican nuestra manera de pensar y actuar." Nos preguntamos si la compulsión al consumo y la hipersexualidad presente en la vida actual funcionaría igual sin la orientación de los medios.

Hasta hace un par de décadas el lamento de los mayores era "La televisión ha convertido el círculo familiar en semicírculo". De esta manera, se cuestionaba cómo la privacidad del hogar y la función de la familia en la formación del individuo se había visto perturbada con la intromisión de un elemento de la tecnología que atentaba contra la tradicional transferencia de valores, ideas y comportamientos, cultura en fin, en el núcleo familiar. Padres e hijos reemplazaban las charlas de sobremesa con la reunión en torno al artefacto que aportaba al hogar nuevos elementos de información y una cuota de fantasía. En nuestros tiempos, el problema se ha tornado más complejo aún, pues además del menor número de horas en que los miembros de la familia coinciden en casa, el uso de los aparatos tecnológicos y de la propia televisión en los hogares se hace por separado. Ya la familia no se reúne en torno al televisor; los medios son diversos y su uso se da en forma individual y aislada; cada quien busca y recibe la información que sus particulares intereses demandan.

Un estudio reciente del Consejo Consultivo de Medios de Comunicación -CONCORTV realizado entre niños de 7 a 16 años a nivel nacional, informa que el $99.9 \%$ de encuestados tiene televisión en su hogar; el 95.5 tiene un aparato de radio y el $61.9 \%$ tiene una computadora, aunque solamente el $50.5 \%$ tiene internet dedicado. En cuanto al consumo diario de los medios por niños y adolescentes, el $86.8 \%$ ve televisión; el $37.7 \%$ escucha radio y el $36.5 \%$ 
navega en internet. Esta dinámica determina la necesidad de una mayor supervisión y control de parte de los padres hacia los contenidos que consumen los hijos menores y las frecuencias en que "se conectan", lo que no es sencillo de lograr, dadas las amplias jornadas laborales y la autonomía que exigen los niños de hoy, a diferencia de la antigua infancia, donde el sometimiento a la autoridad paterna era natural e indiscutible. En este punto, la encuesta revela que el $44.5 \%$ de los niños dijo que sus padres están atentos a que no vean ciertos programas, el $41.3 \%$ indicó a veces y el $14.2 \%$ nunca. $^{6}$

Internet es hoy en día un fenómeno tan necesario y beneficioso como novedoso y virtualmente incontrolable por su gigantismo y anonimia, percibiéndose aún en forma incipiente sus efectos sobre las nuevas generaciones. La encuesta de CONCORTV indica que únicamente el $16 \%$ de los niños encuestados afirmó que nunca navega en Internet, índice que debe estimarse considerando que el rango de edad de los encuestados inicia en los 7 años. En cuanto al uso de internet, la principal actividad reportada después de buscar información para las tareas, es chatear y usar redes sociales $(68.7 \%)$.

Como hemos indicado, la radio y la televisión nacional, resultan ser los medios más utilizados por nuestra población, por lo que merecen un espacio de reflexión y crítica constructiva. Ya el presidente de la República en alguna oportunidad se detuvo a hacer un comentario respecto a los noticiarios televisivos, llamando la atención sobre su contenido no apto para menores, sugiriendo ocuparse de contenidos más edificantes. En consonancia con ello, la encuesta que comentamos reveló que el $88 \%$ de niños y adolescentes opinan que las noticias presentan demasiada violencia. No obstante, la reacción inmediata de los medios fue la defensa de la "libertad de prensa", derecho constitucional que frecuentemente se mal interpreta, como si se tratara de una espada para frenar cualquier intromisión a los criterios de programación que generan buen rating. Particularmente en mi caso, en la necesidad de informarme a través de los noticiarios, he optado por poner el aparato en silencio y prestar más atención a los cintillos que se inserta sobre el tema que a las imágenes de la noticia. Evito así encontrarme con descripciones detalladas de todo tipo de eventos truculentos, interrogatorios a las víctimas de hechos violentos, o situaciones íntimas de conocidos y desconocidos, que por ese medio pasan a la primera condición. Todo ello despierta el morbo inconsciente que existe aún en el ser más civilizado.

6 CONCORTV (2012) Encuesta a Niños y Adolescentes sobre la radio y televisión Peruana. Disponible en: http://www.concortv.gob.pe/file/2012/estudios 
Hasta hace poco pensaba que la alta cuota de violencia en la televisión era una herencia de los años 90, donde muchos medios de prensa y la televisión se esforzaban por distraer la atención nacional mostrándonos alternativamente, un cadáver destrozado, una señorita en prendas minúsculas, vírgenes que lloraban y violadores-asesinos que acechaban en los cerros. Vargas Llosa nos informa que se trata de un fenómeno mundial: "Porque no existe forma más eficaz de entretener que alimentando las bajas pasiones del común de los mortales". Ironiza diciendo: "Una materia que ameniza mucho la vida de la gente es la catástrofe. Todas, desde los terremotos y maremotos hasta los crimenes en serie $y$, sobre todo, si en ellos hay los agravantes del sadismo y las perversiones sexuales" ${ }^{7}$ Daría la impresión de que los años 90 nos trajeron el activo y el pasivo dela modernidad.

El escritor atribuye esta tendencia de los medios al "Apetito asombroso que inconscientemente presiona sobre los medios de comunicación por parte del público lector, oyente y espectador". En este punto me permito discrepar, por aquello del dilema del huevo y la gallina. Considero que en esa afirmación se desliza un desprecio inconsciente por el ciudadano común. Pienso en la gran diversidad cultural de nuestro país y la agresividad de gran parte de los contenidos televisivos (me refiero, claro está a la televisión comercial). Me pregunto si una familia andina, abocada al cuidado de su tierra y el pastoreo de sus animales se sienta por las noches frente al televisor con hambre de sordidez y violencia o si los niños citadinos de la costa se sienten complacidos escuchando durante el almuerzo la descripción de las relaciones íntimas de los "homosexuales modernos" 8 El propio Vargas Llosa ha descrito anteriormente cómo el contenido de los medios influye, transforma y moldea al individuo, lo que me releva de mayores argumentos.

Otro aspecto sobre el cual incide el ensayo que comentamos destaca que la incesante sucesión de noticias e imágenes, derivada de la concepción de la información como espectáculo, impide que los receptores puedan generar una perspectiva crítica sobre lo que ocurre. El enunciado de la noticia interesa en la medida que impacta $y$, causado el efecto, se pasa inmediatamente a otra cosa. De esta manera, el propósito de la información no se vincula a lo solidario, a lo reflexivo ni a lo humano, interesa únicamente atrapar la atención del receptor por el mayor tiempo posible y cuando la atención decae se introduce un nuevo

\footnotetext{
7 Op.Cit.

${ }^{8}$ Homosexuales que en sus relaciones íntimas desempeñan alternativamente el rol femenino y masculino. Visto en un canal de TVenel horario de 2:00 a 3:00 p.m.
} 
hecho llamativo o escandaloso. Por esta razón, podemos ver a una de las periodistas más serias de la televisión anunciando en el noticiero: "Imágenes de impacto", lo que no es más ni menos que una secuencia de accidentes de tránsito ocurridos en países lejanos, personas sin tiempo ni identidad, que vuelan por los aires con las articulaciones desencajadas, una directa cosificación del ser humano. Ni una persona que sufre, ni una sociedad solidaria que acude en su ayuda, tampoco un mensaje preventivo sobre seguridad vial; simplemente un espectáculo que apela al morbo. Este tratamiento en palabras de Vargas LLosa, nos condena a una pasiva receptividad, a la atonía moral y anomia psicológica en que suelen ponernos las Ficciones o los programas de consumo masivo cuyo único propósito es entretener. ${ }^{9}$ Tal perspectiva en un país como el nuestro, aún adolescente en consciencia y participación ciudadana es sumamente desalentadora, siendo imperativo motivar en los medios de comunicación una revisión de sus propósitos y acciones.

Una investigación reciente sobre el efecto de los contenidos violentos en las personas, sostiene que los espectáculos de este tipo exacerban y potencian la agresividad de los espectadores que neurológicamente se hallan predispuestos a desplegar conductas violentas. En cambio, en las demás personas que genéticamente cuentan con patrones de control adecuados, la recepción de la violencia genera rechazo. No obstante, consideramos que una exposición reiterada a la violencia desde la primera infancia, de seguro generará alteraciones en la personalidad del individuo. Al respecto, Gianfranco Bettetini, investigador italiano especialista en la teoría y técnica de la comunicación de masas, da cuenta de por lo menos tres efectos a largo plazo: ${ }^{10}$

1) Un efecto mimético directo: Niños y adultos expuestos a grandes dosis de espectáculos violentos pueden llegar a ser más agresivos o a desarrollar, con el tiempo, actitudes favorables al uso de la violencia como medio para resolver los conflictos.

2) Un efecto indirecto: La insensibilización. Los espectadores, sobre todo los niños, expuestos a grandes cantidades de violencia en la pantalla, pueden hacerse menos sensibles a la violencia real del mundo que les circunda, menos sensibles al sufrimiento ajeno y más predispuestos a tolerar el aumento de violencia en la vida social.

${ }^{9}$ Op.Cit.

10 La televisión: Espejo o cristal de aumento? Gianfranco Bettetini. http://www.humanitas.cl/html/biblioteca /articulos/d0190.html 
3) La sobreestimación del público del índice de violencia real, generándose la creencia de que la sociedad en la que vive se caracteriza por un elevado grado de violencia y peligrosidad. En este caso, no aumentarían los comportamientos violentos sino la reacción de miedo ante ellos.

Lo valioso del estudio citado es que no solamente disecciona los efectos de la violencia sino que además concluye con una pauta de recomendación: Es necesario disminuir el nivel de violencia presente en los medios, sobre todo, interviniendo sobre la modalidad de su representación: "evitando que aparezca subrayada, destacada en primera página, descrita minuciosamente, encarnada en pseudohéroes, convertida en tema de inútiles pseudoencuestas y de inconscientes apologías". Qué duda cabe que la sociedad moderna tiene altos componentes de violencia de todo tipo: la violencia explícita y directa de los crímenes y los accidentes, la violencia de género al interior de las familias, la violencia sofisticada de las películas, la violencia de la pornografía que asalta a los niños en internet, entre otras que sería largo enumerar. Compete a los medios la responsabilidad social de mantener al público objetivamente informado y promover la actuación pertinente de las autoridades. En ese cometido, es necesario evitar hacer una apología de la conducta violenta o mostrarla con el propósito velado de enganchar el morbo del consumidor - $\mathrm{La}$ palabra morbo significa estado de enfermedad o alteración de la salud-Todos coincidimos en que aspiramos a una sociedad emocionalmente sana, consciente de los problemas y participativa en las soluciones. A esos efectos, las recomendaciones de Bettetini son absolutamente pertinentes. No es prudente realizar un reportaje sobre la boda de un criminal sentenciado ya que el mensaje que se transmite es sumamente ambiguo y su crimen pasa a ser una mera anécdota.

En cuanto a la radio, llama la atención que el periodismo se ejerza todavía en base a la improvisación y no a la preparación responsable en el campo de la comunicación y las ciencias sociales. Aun tratándose de profesionales en la materia, salen a la luz comportamientos y opiniones que hacen tabla rasa de los derechos humanos; en particular de los derechos de las mujeres, niños y ancianos. Escucho un extraño elogio del conductor a su compañera afirmando que: "Está tan buena, que si no fuera su amiga ya estaría violada". Pese a que ese mismo conductor presenta un mensaje claro y positivo contra el consumo de drogas, trasluce en muchas de sus intervenciones mensajes sexistas como el anotado. Durante años se propala también una secuencia que consiste en hacer bromas telefónicas a personas incautas, llevando a la víctima la 
exasperación de forma tal que responde al conductor con insultos de todo tipo. En cumplimiento a las normas de radio y televisión que prohíben propalar contenidos obscenos, la emisora filtra las palabras subidas de tono. Pero ¿Quién censura a los instigadores de la agresión? Una respuesta anónima en un foro de Internet responde por si sola: "Si no te gusta el programa, cambias el dial o apagas tu radio, prendes el TV o mejor aún...lees un libro" ${ }^{11}$ Cabe señalarse que la reciente encuesta de CONCORTV revela que los oyentes rechazan mayoritariamente la emisión de insultos y frases en doble sentido en la radio.

Para terminar en este punto, y en atención a la gravedad de la situación, traigo a colación una secuencia de otro programa que los conductores denominan: "Quémalo al aire". Allí el público, básicamente adolescente, es invitado a denostar a un tercero, que puede ser un compañero de colegio, un vecino, una ex enamorada etc. con la frase: "Que todo el mundo se entere que..." Por supuesto, gran parte de lo que allí se dice, tipifica automáticamente los delitos de injuria y difamación por medio de prensa, situación que a los conductores y directivos de la radio no les preocupa analizar.

Es momento de señalar que la libertad de prensa e información es, en efecto, un derecho constitucional del primer nivel, y precisamente por su trascendencia y amplitud debe cumplir condiciones de legitimidad en atención a sus fines, correspondiendo limitarse cuando afecte otros derechos constitucionales igualmente respetables. Siendo así, la libertad de trabajo, la libertad de expresión y la voluntad de generar esparcimiento a través del humor no puede constituirse en un atentado contra la salud física y emocional de las personas ni en una invitación a transgredir los derechos de otros.

En materia normativa, la Constitución Política del Estado establece en su artículo $14^{\circ}$ que Los medios de comunicación social deben colaborar con el Estado en la educación y en la formación moral y cultural. Sobre esa base la Ley de Radio y Televisión ${ }^{\mathbf{1 2}}$ establece como principios para la prestación de los servicios de radiodifusión: La defensa de la persona humana y el respeto a su dignidad; la defensa del orden jurídico democrático, de los derechos fundamentales y de las libertades consagradas en los tratados internacionales y la Constitución Política y la protección y formación integral de los niños y adolescentes, así como el respeto a la

\footnotetext{
11 La página de la Sociedad Nacional de Radio y Televisión registra una queja formulada en el año 2007, contra el programa "Arriba los fonos" mas no consta la resolución expedida.http://www.snrtv.org.pe/audiencia.php ${ }^{12}$ Ley 28278 , promulgada el 15 de junio de 2014.
} 
institución familiar. Tales principios tienen igual nivel de trascendencia y obligatoriedad que el de la libertad de expresión, pensamiento y opinión. Asimismo, se señala como fines del servicio de radiodifusión "Satisfacer las necesidades de las personas en el campo de la información, el conocimiento, la cultura, la educación y el entretenimiento, en un marco de respeto de los deberes y derechos fundamentales, así como de promoción de los valores humanos y de la identidad nacional" ${ }^{13}$. Consecuentemente, las actividades de la radio y televisión deben armonizar con los principios generales que su norma rectora consagra.

No debemos olvidar que las empresas de radio y televisión no constituyen meros negocios privados; son más bien y fundamentalmente, servicios públicos que el Estado ha delegado mediante la concesión del espectro radioeléctrico, bien intangible y escaso, que permite la operatividad de las emisoras de radio y televisión. En cuanto a la libertad de empresa, la Constitución Política, antes acotada establece que ésta no debe ser lesiva a la moral, la salud y la seguridad públicas. ${ }^{\mathbf{1 4}}$

De acuerdo con la normativa antes enunciada, se ha diseñado un mecanismo para el tratamiento de las infracciones al deber ser de los medios de comunicación, a través del Comité de Solución de Quejas de la Sociedad Nacional de Radio y Televisión y, en segunda instancia, del Tribunal de Ética al efecto constituido. Los demandantes deben acompañar a su solicitud de rectificación o queja las copias de las publicaciones motivo de su reclamo. El tribunal remite la queja al medio demandado y le da un tiempo determinado para su respuesta; en caso que el medio decida hacer la rectificación, se archivará la queja si el ciudadano se siente satisfecho con ello. De lo contrario, el tribunal, si encuentra fundado el reclamo, emite una resolución que debe ser publicada en el medio denunciado. ${ }^{15}$ Las sanciones posibles son amonestación, difusión de un aviso rectificatorio y multa. La existencia de este procedimiento es desconocida para el $62 \%$ de encuestados en el año 2014.

La actuación de los referidos órganos ha sido acertada en muchos casos, pero en otros ha quedado de manifiesto la tolerancia excesiva a determinados comportamientos lesivos a derechos constitucionales. Es así que, ante

\footnotetext{
13 Ley 28278, Art. $4^{\circ}$.

${ }^{14}$ Constitución Política del Perú, Art. $59^{\circ}$.

15 Disponible en: http://www.larepublica.pe/15-12-2011/la-autorregulacion-de-los-medios-una-experiencia-queavanza-en-el-pais
} 
denuncias por actos de discriminación racial, como el caso de los personales "Negro Mama" y "Paisana Jacinta" el Tribunal resolvió que" no afectan valores esenciales y la dignidad de las personas y corresponden al ejercicio legítimo de la libertad de expresión, en una de sus variantes: la expresión artística a través del humor". Tal criterio ha quedado rebatido con el pronunciamiento del Comité para la Eliminación de la Discriminación Racial de las Naciones Unidas, que decidió que el programa Paisana Jacinta es ofensivo, denigrante y refuerza estereotipos negativos sobre las mujeres y los pueblos indígenas. Se destacó además que este programa demostraba un problema de fondo, en una sociedad que percibe este tipo de estereotipos racistas como algo "natural", podemos agregar que, prueba de ello, era precisamente el alto rating con que contaba.

En los casos que involucran a niños y adolescentes, existe la idea equivocada de que sus derechos únicamente se afectan cuando se expone su imagen, por lo que el periodista cuida de difuminar el rostro del niño a quien ha interrogado sobre las circunstancias en que fue asesinada su madre o de cómo se hizo sicario. Es importante destacar que los padres, el Estado y la colectividad nos hallamos obligados a preservar la salud e integridad física y emocional de los menores de edad por ser personas en formación. En consonancia con ello, el Pacto de Autoregulación de la Sociedad Peruana de Radio y Televisión recoge en el numeral 1.2, una disposición especial que prohíbe "Presentar la figura humana, en especial la mujer y el menor, en situaciones indecorosas, deshonestas o agraviantes". Esta disposición ha permitido sancionar a un canal de televisión el tratamiento del caso de un niño que fue entrevistado sobre los pormenores de la violación sexual sufrida de parte de su padre ${ }^{16}$. Debe tenerse presente que, inclusive la presencia y asentimiento de los padres para esta clase de abordajes, carecería de trascendencia por cuanto se trata de un acto claramente vulneratorio de derechos. En otros casos, se han dictado decisiones saludables sancionando la infracción al horario de protección del menor así como determinados contenidos de los programas reality que cuentan con el $79 \%$ de audiencia juvenil, tal como lo revela la encuesta de CONCORTV.

Adicionalmente, sin perjuicio de la autoregulación de la prensa a través de sus órganos antes aludidos, el Código de los Niños y los Adolescentes contempla la figura del proceso sobre Contravención a los Derechos del Niño, destinado a sancionar todo tipo de actos lesivos a los derechos de niños y

16 Resolución 016-2012-SNRTV, de fecha 21 de diciembre de 2012. 
adolescentes que no alcance la gravedad de un delito. ${ }^{17}$ Esta figura procesal resulta ser sumamente útil por su amplitud, constituyéndose en un espacio de protección efectiva a la infancia tanto por las medidas de protección que pueden adoptarse directamente a favor de los afectados como por la réplica que se genera a través de la jurisprudencia. En materias como esta sería importante contar con la alianza de los medios de comunicación para difundir las buenas prácticas del Ministerio Público y Poder Judicial e informar a la colectividad sobre los límites que deben observarse en la interacción con los niños y adolescentes y las sanciones que podrían generarse en caso de que se atente contra sus derechos.

Para finalizar, podemos señalar que pese al panorama general que hemos presentado y del que no podemos escapar por mandato de la globalización, existen algunos elementos estructurales alentadores. La existencia del Consejo Consultivo de Medios de Comunicación - CONCORTV como responsable de propiciar buenas prácticas en la radio y la televisión del Perú así como la presencia de instancias para el tratamiento de denuncias contra los medios de comunicación, como son el Comité de Solución de Quejas de Radio y Televisión y el Tribunal de Ética debe alentar a los ciudadanos a una mayor participación para contribuir a la construcción de un sistema de medios que cumpla las finalidades que la Constitución le asigna.

Lima, octubre de 20014.

\section{Referencias}

- CONCORTV. (2012) Encuesta a niños y adolescentes sobre la radio y televisión peruana. Disponible en:

http//www.concortv.gob.pe/index.php/investigaciones/encuestas/10 41-2012-encuesta-a-niños-y-adolescentes-sobre-la-radio-y-televisiónperuana.html

- Lipovetsky Giles y Jean Serroy. (2010) La cultura del mundo. Respuesta a una sociedad desorientada. Editorial Anagrama. Barcelona.

- Vargas Llosa, Mario. (2012) La Civilización del Espectáculo. Editorial Alfaguara. Madrid.

17

Código de los Niños y los Adolescentes. Art. $69^{\circ}$ y $71^{\circ}$. 